\title{
Combined Scar Subcision and Autologous Fat Grafting for Correction of Atrophic Depressed Scars of the Face
}

\author{
AYMAN FIKRY, M.D.; AHMED M. ALY, M.D. and AHMED A. MAHMOUD, M.B.B.Ch. \\ The Plastic and Reconstructive Surgery Unit, General Surgery Department, Faculty of Medicine, Zagazig University, Zagazig
}

\begin{abstract}
Introduction: Atrophic depressed scars of the face are a common cosmetic problem; the main task is scar improvement with least invasive modalities to achieve nearly ideal scar criteria, among these modalities is subcision. Simple filling the depression or subcision alone will not be enough to obtain long lasting result.
\end{abstract}

Objective: To assess the efficacy of combined scar subcision with Nokor ${ }^{\circledR}$ needle $18 \mathrm{G}$ and simultaneous lipofilling for the correction depressed linear scars of face.

Method: In this case series, 20 adult patients [18 males and 2 females, ranging between 18-45 years old (Mean \pm SD, $33.2 \pm 9.98$ )], suffering from facial atrophic depressed, (post traumatic or surgical scars) underwent our elected procedure.

Results: There were statistically a high significant difference among the studied group between preoperative and postoperative scar as regarding total score of the scar $(p<0.001)$, and overall appearance of the scar, leading to a high patient satisfaction rate. Unfortunately the results were unsatisfactory in four cases.

Conclusion: This combined technique had significantly improved atrophic depressed linear scars of the face; it could be considered a simple, inexpensive, and minimally invasive realistic modality for scar management.

Key Words: Facial depressed atrophic linear scars - Subcision - Lipofilling - Nokor needle.

\section{INTRODUCTION}

Scar is defined as any mark remains after a deviation in the orderly pattern of wound healing process [1,2]. It is inevitable result of injury to skin, whatever intentional as elective or urgent surgery, accidental traumatic insults or burns $[3,4]$.

Atrophic depressed scars, occur when early wound healing conditions are suboptimum; such as wound seroma, hematoma, infections, or improper surgical repair, all of these potentialities lead to inflammatory collagen destruction with dermal atrophy, overlying thinned epidermis and depression under healing skin incisions [2,5], addi- tionally atrophic depressed scars may result from loss of subcutaneous fat [3].

These Scars are often tethered and fixed because of scarring process extending in the tissues underneath the skin, and fascia. This likely result in residual depressed scarring, with unsightly appearance $[4,6]$.

Atrophic scars are initially erythematous and with time they become fully mature and increasingly depressed and fibrotic [2,5], with an alteration of skin quality, color, vascularity, nerve supply and chemical properties [7].

Existing options for the improvement of the depressed scars include scar revisional surgery [8]. Nowadays the goal is no longer tissue replacement, but rather tissue rehabilitation which attempts to revitalize and restore damaged skin [9], in order to obtain a uniform smooth flat surface [8].

Rising up of depressed scars may require tissue augmentation [3]. Simply filling the depression with autologous fat or other fillers will fail to raise the scar bottom off the deep scar attachment unless fibrous bridles are divided [6,10]. At the same time, subcision alone will not be enough to obtain long lasting result due to reattachment of the skin to the underlying scar [6]. In consideration of these information, subcision is initially done then concomitant volumetric filling to obtain a permanently flat scar $[6,10]$.

The purpose of this study was to evaluate the outcome of combined Nokor needle scar subcision and autologous lipofilling of depressed facial scars.

\section{PATIENTS AND METHODS}

The present study was interventional study (pre-post), carried out on 20 adult patients (18 males and 2 females, between July 2015 and Oc- 
tober 2016, their ages ranged from 18-45 years old, Table (1) summarizes patients' data. Patients were suffering from old atrophic depressed, linear, and discrete singular scars in the face more than 6 months after surgery or trauma, they were selected from the Outpatient Clinic of Plastic Surgery of Zagazig University Hospitals. All participating patients were informed about the steps of the procedure and possible complications and consented, after approval of the Ethical Committee in Zagazig University.

While Patients with recent immature scars, or any other type rather than depressed scars, or history of hematological disorders, or mentally or psychologically disordered or prior chemotherapy or radiotherapy, or keloid formation tendency were excluded from the study.

Operational design: The scar should be soft, supple, and nontender, representing no significant residual erythema, edema, or induration [12]. Strict asepsis was observed, with infiltration of local or regional anesthesia with adrenaline 1:200,000 for hemostasis.

1- Wound Subcision: Preoperative applying of icepacks to the area of wound to avoid hematoma formation. Nokor ${ }^{\circledR}$ Needle 18 G 11/2 inch (Fig. 1) was inserted at periphery of the scar and advanced underneath it parallel to skin surface, usually mid to deep dermal, or rarely in the sub-dermal fat interface.

Then the needle was swept widely underneath the scar, from side to side in a fanlike horizontal motion, to cut the fibrotic bands, and releasing the tied scar bottom from the tethering fibrous, a characteristic clicking was heard, indicating that subcision was being properly conducted. In large scars, 2-3 entry sites were needed to complete undermining of scars.

2- Fat harvesting (liposuction): It was harvested by using a blunt tipped $3 \mathrm{~mm}$ cannula and syringe method by tumesant technique; from the lower abdomen, lateral hips, thighs, or medial knees. The collected fat was centrifuged at $3000 \mathrm{rpm}$ for $1 \mathrm{~min}$. The aqueous layer and oily layer were discarded, and the fat cells were kept in $3 \mathrm{ml}$ luer lock syringe for injection.

3- Fat injection: The fat was gently injected with a $1-1.5 \mathrm{~mm}$ cannula through the same openings for subcision, it was injected while simultaneously withdrawing the cannula out of the incision, in tunnels into the level of the subcision area, extending for $1 \mathrm{~cm}$ on either side, also be injected into tunnels at other levels of the tissues. The end point of the injection was when the depression is obliterated. It was necessary to over-inject the scar since some fat be would lost by absorption [13]. A dressing was put in place to compress all around the treated area, avoiding pressing on the scars, to prevent fat displacements and re-adherences of the scar to the underlying fascia (Figs. 2-5).

Follow-up examinations: The pre- and postoperative evaluation of the depressed scar had included the use of the qualitative grading system (Stony Brooks scar evaluation scale) by Singer et al. [11] Table (2), and photographic documentation (up to 6 months). The degree of scar improvement was estimated according to percentage of increment of postoperative total score as follow: Poor: If it was $20 \%$, good: If it was $40 \%$, very good: If it was $60 \%$, and excellent: If it was $80 \%$ increase total scar score.

\section{RESULTS}

This technique was successfully done without injury to the skin surface, or evidence of infection. The range of amount of injected fat was $1-6 \mathrm{~mm}$. There were accompanying post-operative mild to moderate edema and ecchymosis which resolved in the early days after the procedure. There were statistically a high significant difference among the studied group between preoperative and postoperative scar quality regarding color, depth and overall appearance of the scar as well as the scar score $(p<0.001)$. Unfortunately the results were unsatisfactory (poor) in four cases, Table (3) shows the results.

Table (1): Patients' data.

\begin{tabular}{cl}
\hline Variable & Cases $(\mathrm{n}=20)$ \\
\hline Age (year): & \\
Mean \pm SD & $33.2 \pm 9.98$ \\
Range & $18-45$ \\
Sex: & \\
Female & $2(10 \%)$ \\
Male & $18(90 \%)$ \\
\hline
\end{tabular}

Table (2): Stony Brooks scar evaluation scale.

Stony Brooks scar evaluation

\begin{tabular}{ll}
\hline (i) Width of the scar: $>2 \mathrm{~mm}-\mathcal{s m m}$ & $(0-1$ points $)$ \\
(ii) Height: Depressed or elevated-flat & $(0-1$ points $)$ \\
$\quad$ (compared to surrounding) & $(0-1$ points $)$ \\
(iii) Color: Darker - same or lighter & $(0-1$ points $)$ \\
(iv) Hatch or suture marks: Present - absent & $(0-1$ points $)$ \\
(v) Overall appearance: Poor - good & \\
\hline
\end{tabular}

Total score:

0 to 5 points 
Table (3): Pre \& post-operative score of the scar among the studied group.

\begin{tabular}{|c|c|c|c|c|c|c|}
\hline \multirow[t]{2}{*}{ Variable } & \multicolumn{2}{|c|}{$\begin{array}{c}\text { Pre- } \\
\text { intervention } \\
(n=20)\end{array}$} & \multicolumn{2}{|c|}{$\begin{array}{l}\text { Post- } \\
\text { intervention } \\
(n=20)\end{array}$} & \multirow[t]{2}{*}{$\mathrm{MC}$} & \multirow[t]{2}{*}{$p$} \\
\hline & No. & $\%$ & No. & $\%$ & & \\
\hline \multicolumn{7}{|l|}{ Score: } \\
\hline 0 & 3 & 15 & 0 & 0 & & \\
\hline 1 & 7 & 35 & 4 & 20 & 18.9 & $p<0.001$ \\
\hline 2 & 4 & 20 & 0 & 0 & & \\
\hline 3 & 6 & 30 & 0 & 0 & & \\
\hline 4 & 0 & 0 & 6 & 30 & & \\
\hline 5 & 0 & 0 & 10 & 50 & & \\
\hline \multicolumn{5}{|l|}{ Score: } & \multirow{3}{*}{$\begin{array}{l}\text { Paired W } \\
3.57\end{array}$} & $p<0.001$ \\
\hline Mean士 SD & \multirow{2}{*}{\multicolumn{2}{|c|}{$\begin{array}{c}1.65 \pm 1.09 \\
0-3\end{array}$}} & \multirow{2}{*}{\multicolumn{2}{|c|}{$3.9 \pm 1.55$}} & & \\
\hline Range & & & & & & \\
\hline
\end{tabular}

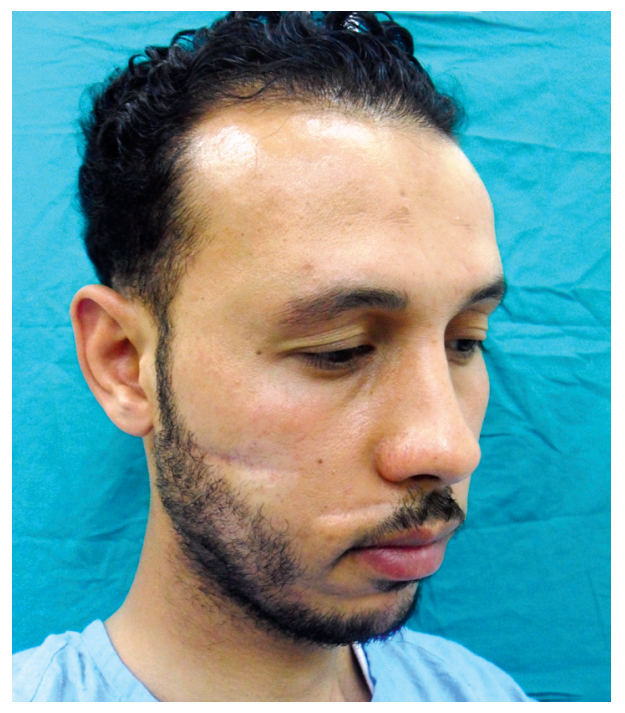

Fig. (2A): Preoperative view of 32 years old man with two depressed post-traumatic scars on his right cheek.

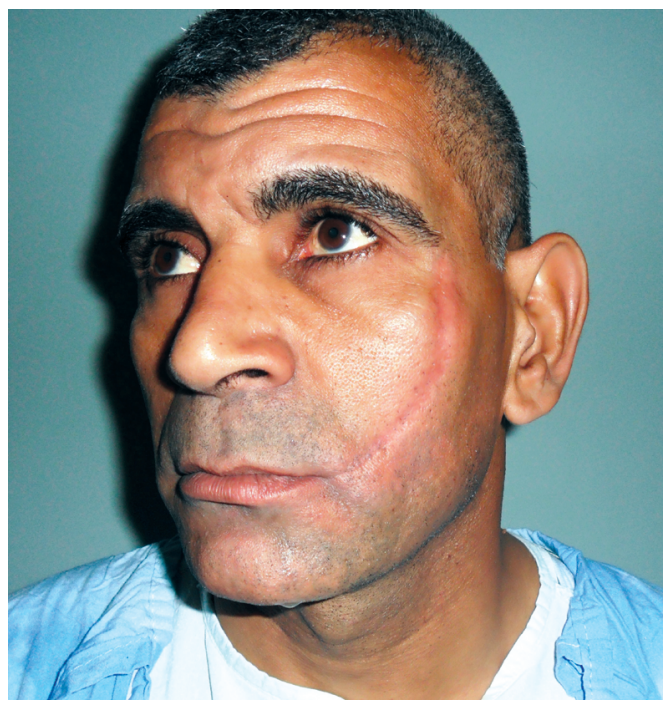

Fig. (3A): Preoperative view of 42 years old man with depressed traumatic scars on his left cheek surgically revised one year before.

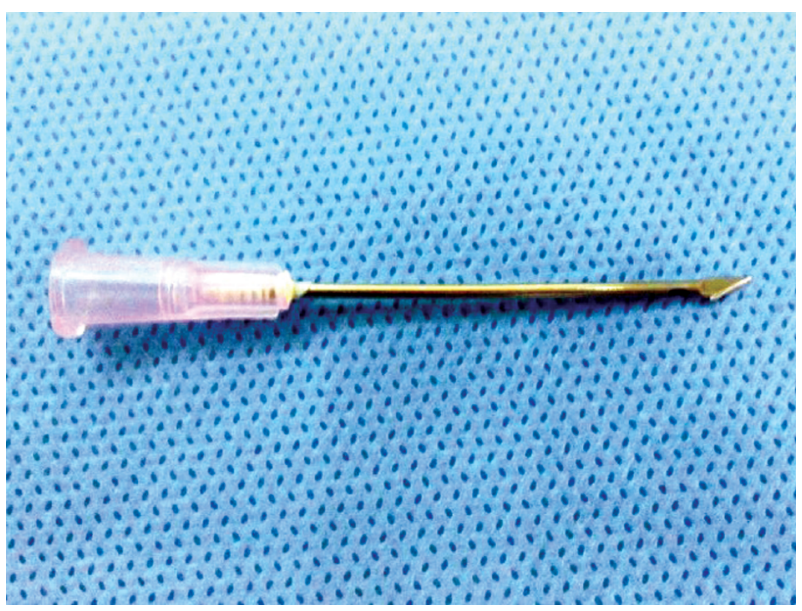

Fig. (1): Nokor® Needle 18 G 1/1/2 inch.

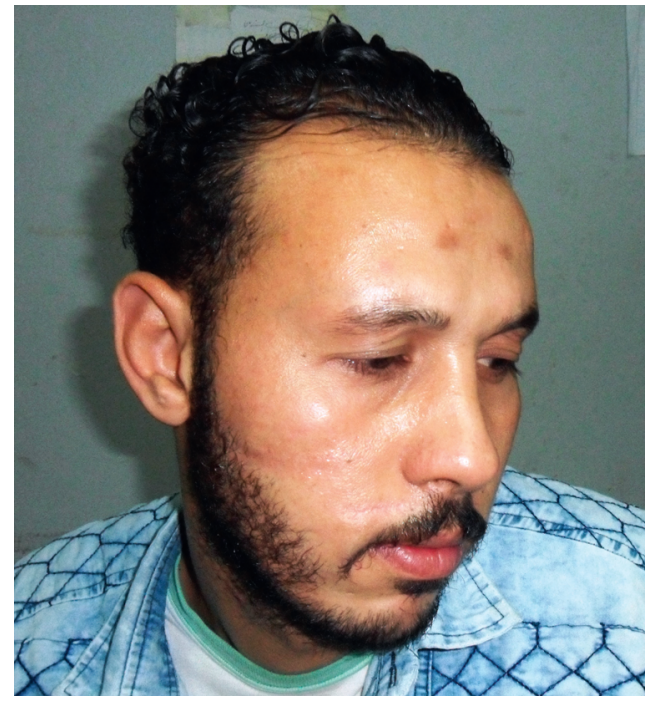

Fig. (2B): Postoperative view 6 months later after the procedure with very good improvement and no recurrence.

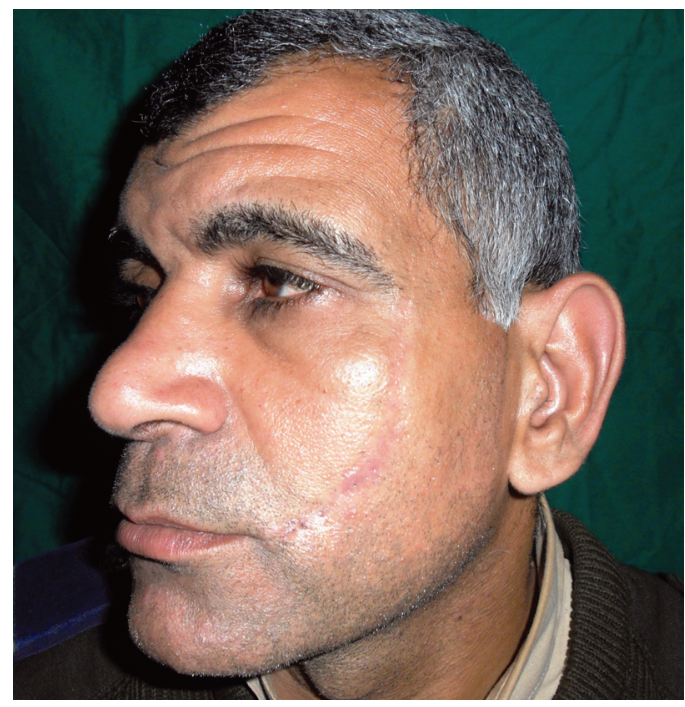

Fig. (3B): Postoperative view 5 months later after the procedure with good improvement. 


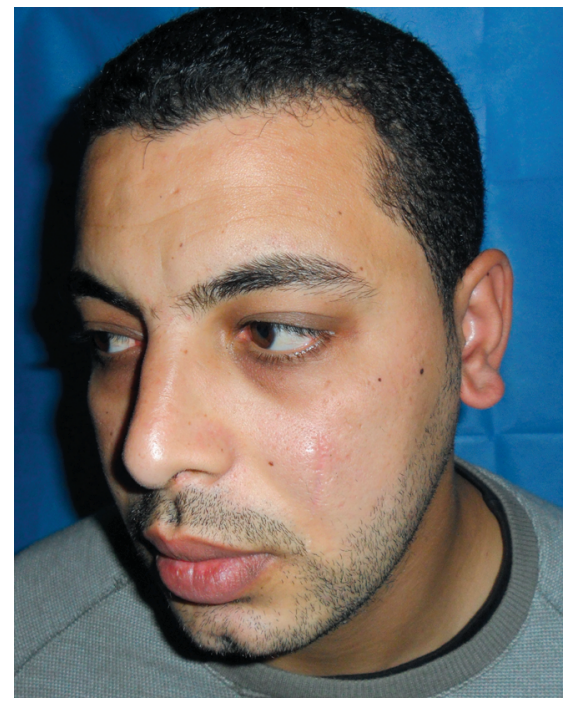

Fig. (4A): Preoperative view of 26 years old man depressed traumatic scars on his left cheek.

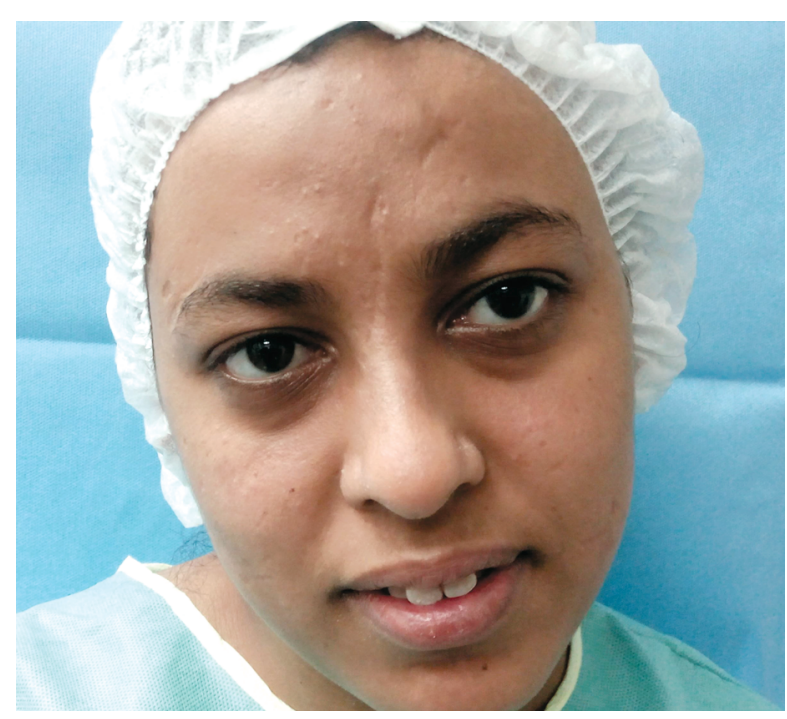

Fig. (5A): Preoperative view of 19 years old woman with depressed traumatic scars of on her forehead.

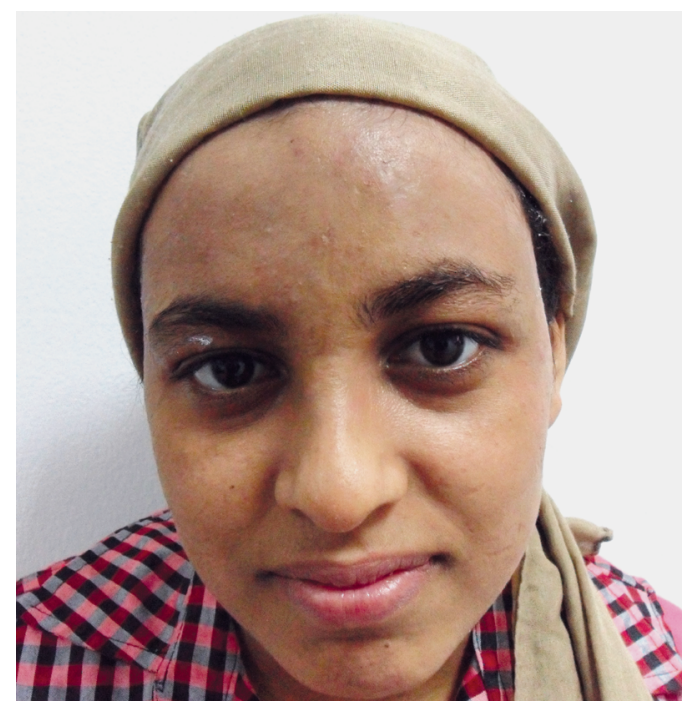

Fig. (6): Overall appearance of the scar pre and post-operative among the studied group.

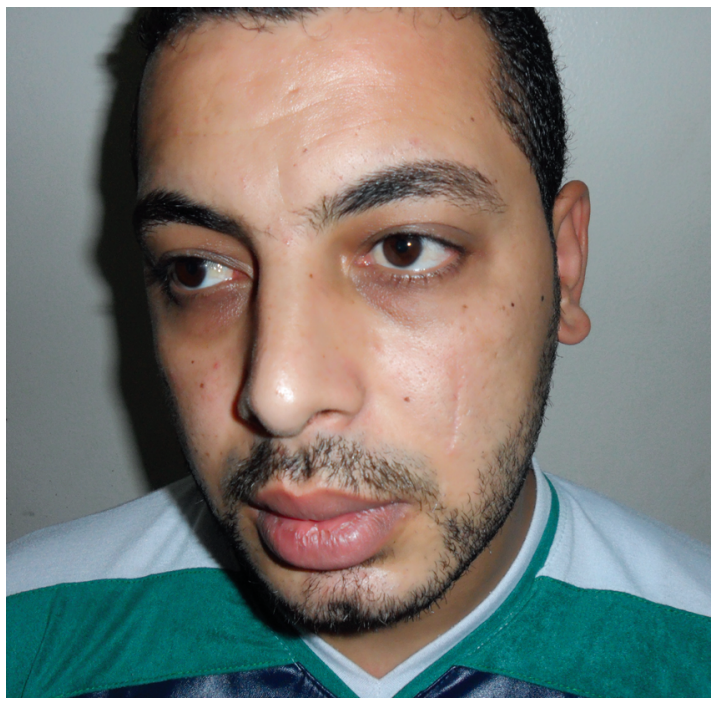

Fig. (4B): Postoperative view 4 months later after the procedure with very good improvement.

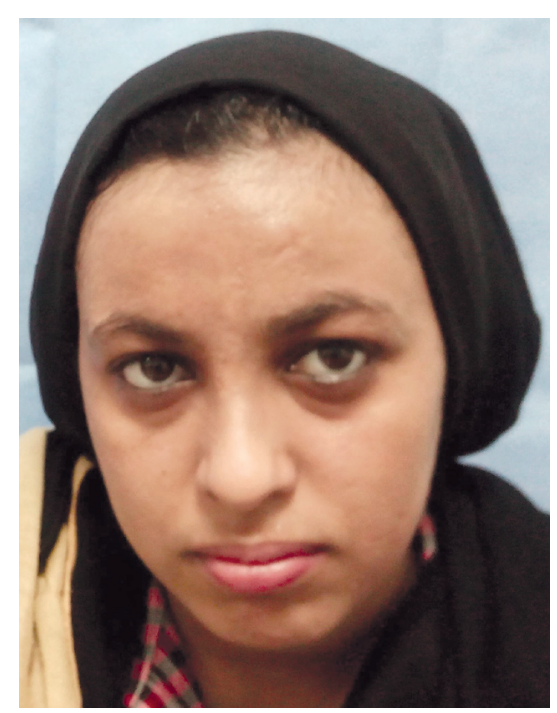

Fig. (5B): Postoperative view 4 months later with very good improvement.

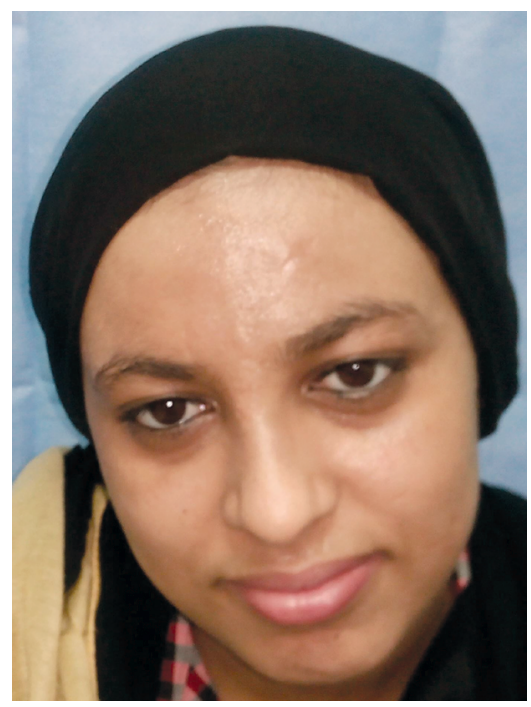




\section{DISCUSSION}

Visible cutaneous scarring of the head and neck region bear a heavy emotional burden on patients. The physical and psychological impact of scars can be profound, and lead to low self-esteem $[4,14]$. Facial scarring represents a significant therapeutic challenge for plastic surgeons [15].

Different surgical treatment modalities are designed to optimize the characteristics of the scar toward a more ideal one, which after complete maturation is narrow, flat, and has a good color match with adjacent skin $[4,12]$, one of these modalities is subcision.

Since its original description by Orentreich and Orentreich [16], Subcision gained a wide popularity as a surgical technique for the treatment of cutaneous depressions, scars and wrinkles [17].

Several tools had been used for doing subcision, starting with usage of a tribeveled hypodermic needle by Orentreich and Orentreich [16], while De Benito et al., used a dissecting cannula [8], Sulamanidze et al. devised a wire attached to a straight needle [19], Lau and Offer used a Beaver tympanoplasty blade [20], and Lee and Sung devised epidural needle and vicryl Sutures [21].

In the current study, subcision was done by using an 18-gauge 1.5 inch Nokor Admix needle which was effectively sharp cutting fibrous tissue beneath the depressed scar leading to release of adherent scar bottom, the same finding was observed by other researchers such as Al-Ghamdi [22], and Soirefmann and Mazzuco [17].

During the procedure of subcision, after successful release of anchoring fibrous attachments, the Tethered base of depressed scars floats upward and a recess or pocket is created, into which blood and serous exudate seeped inducing fibroblast proliferation and collagen neogenesis $[\mathbf{1 3 , 1 0 ]}$. The unsuccessful results of subcision were attributed to reattachment of the roof to base of the subdermal pocket, and re-depression of scar recurs again [23].

Attempts had been done to keep this sub-dermal space open by filling it with exogenous material such as injectable filler materials of various types, artificial dermal material, or by filling it with autologous tissue such as fat micro-droplets or dermal grafts $[\mathbf{1 0 , 2 3 , 2 4 ]}$.

The patient's lipoaspirate, in many ways, is an ideal filler than other biodegradable or permanent one, not only as a volumetric bio-filler to fill the depression, but also it contains mesenchymal stem cells, and growth factors such as, basic fibroblast growth factor (bFGF), insulin-like growth factor1 (IGF-1), vascular endothelial growth factor (VEGF), and platelet-derived growth factor (PDGF) [25], also it improves microcirculation, and induces neoangiogenesis leads to better blood flow in the deeper dermal layers [26] improving the scar quality.

On the other hand, Harandi et al., [27] had attempted to improve the subcision efficacy by performing complementary repeated suction sessions on the skin surface in the days following subcision, but he mentioned that, suction had increased the of duration of bruising, swelling, and discoloration.

In this study; Stony Brooks scar evaluation scale was used for the outcome assessment before and after of our procedure. Singer et al., proved that, this measuring scale is highly reliable, feasible, and valid in measuring the long-term improvement of scars, in which increased total score correlates with degree of scar improvement [11].

In the current study, it had been demonstrated that scar subcision with concomitant autologous lipofilling represent an excellent procedure for enhancing the general appearance and aesthetic improvement of treated depressed scars on the face, which led to a high patient satisfaction rate. These results agreed with the findings of other researchers, such as Adly et al., who investigated the effect of core fat graft injection in depressed scar [28], and Pallua et al., who proved Improvement of facial scar appearance and microcirculation by autologous lipofilling tested by laser Doppler spectrometry [26].

\section{Conclusion:}

The concomitant autologous fat injection after Nokor needle subcision ensures complete subcision, augments the depression, and prevents reattachment, achieving a long lasting flat scar in a short time. This combined technique had statistically increased significant and persistent improvement in atrophic depressed linear scars of the face, it could be considered a simple, inexpensive, and minimally invasive realistic modality for scar management; it is nearly painless procedure with zero downtime, so the patient can resume his or her activities immediately after the procedure.

\section{REFERENCES}

1- Khetarpal S., Dover J.S. and Arndt K.: The evolution and current best treatments for traumatic, surgical, and burn Scars. Curr. Derm. Rep., (laser therapy: Jagdeo J., section editor), 5: 228-31, 2016. 
2- Sobanko J.F. and Alster T.S.: Laser treatment for improvement and minimization of facial scars. Facial Plast. Clin. N. Am., 19: 527-542, 2011.

3- Dockery G.D.: Scars. In: Dockery G. and Crawford M. (eds) Lower Extremity Soft Tissue \& Cutaneous Plastic Surgery $2^{\text {nd }}$ edn, Saunders Ltd., 389-410, 2012.

4- Mobley S.R. and Sjogren P.P.: Soft Tissue Trauma and Scar Revision, Facial Plast. Surg. Clin. N. Am., 22: 639651, 2014.

5- Justiniano H., Willey A. and Kilmer S.L.: Scars, Keloids, and Stretch Marks. In: Raulin C. and Karsai S. (eds.) Laser and IPL Technology in Dermatology and Aesthetic Medicine, Springer-Verlag Berlin Heidelberg, 177-185, 2011.

6- Shiffman M.A.: Subcision with Fat Transfer. In: Shiffman M.A. (ed.) Autologous fat transfer, Springer-Verlag Berlin Heidelberg, 65-68, 2010.

7- Breathnach S.M. and McGrath J.A.: Wound healing. In: Burns T., Breathnach S., Cox N., Griffiths C. (eds). Rook's textbook of dermatology. $7^{\text {th }}$ ed. Oxford Blackwell Science Ltd., (11.1-11.25), 2004.

8- De Benito J., Fernandez I. and Nanda V.: Treatment of depressed scars with a dissecting cannula and an autologous fat graft. Aesth. Plast. Surg., 23: 367-370, 1999.

9- Tredget E.E., Levi B. and Donelan M.B.: Biology and principles of scar management and burn reconstruction. Surg. Clin. North Am., 94 (4): 793-815, 2014.

10- Safonov I.: Atrophic Scars and Stretch Marks: Atlas of Scar Treatment and Correction, Springer-Verlag Berlin Heidelberg, 1-95, 2012.

11- Singer A.J., Arora B., Dagum A., Valentine S. and Hollander J.E.: Development and validation of a novel scar evaluation scale. Plast. Reconstr. Surg., 120 (7): 18921897,2007

12- Shockley W.W.: Scar revision techniques, Operative Techniques in Otolaryngology, 22: 84-93, 2011.

13- Christopher M.E., Payne R. and Verner I.: Fillers and soft tissue augmentation. In Katsambas A.D. et al. (eds), European Handbook of Dermatological Treatments, Springer-Verlag Berlin Heidelberg, 1191-1216, 2015.

14- Levine E., Degtis L., Pruzinsky T., et al.: Quality of life and facial trauma, psychological and body image effects. Ann. Plast. Surg., 54: 502-510, 2005.

15- Geraghty L.N. and Rahman Z.: Treatment of Surgical Scars with Laser Therapy, Curr. Derm. Rep., 5: 143-149, 2016.

16- Orentreich D.S. and Orentreich N.: Subcutaneous inci- sionless (subcision) surgery for the correction of depressed scars and wrinkles. Dermatol. Surg., 21 (6): 543-549, 1995.

17- Soirefmann M. and Mazzuco R.: Subcision®: In Tosti A., Hexsel D. (eds.), Update in Cosmetic Dermatology, Springer-Verlag Berlin Heidelberg, 4: 51-64, 2013.

18- Shiffman M.A.: Facial Augmentation with Autologous Fat. In: Prendergast P.M. and Shiffman M.A. (eds.), Aesthetic Medicine Springer-Verlag Berlin Heidelberg, 31: 347-355, 2011

19- Sulamanidze M.A., Shiffman M.A. and Sulamanidze G.M.: Management of Facial Rhytids by Subcutaneous Soft Tissue Dissection. Int. J. Cosmet Surg. Aesthetic Dermatol., 2 (4): 255, 2000.

20- Lau Y.S. and Offer G.J.: Treatment of Soft Tissue Contour Defects by a Combination of Surgical Subcision with a Beaver Tympanoplasty Blade and Autologous Fat Grafting, Aesth. Plast. Surg., 34: 406-407, 2010.

21- Lee S. and Sung K.: An alternative to the wire scalpel for nasolabial fold subcision: A Preliminary Study Using a Tuohy Epidural Needle and Vicryl Sutures, Aesth. Plast. Surg., 40: 846-849, 2016.

22- Al Ghamdi K.M.: A Better Way to Hold a Nokor Needle during Subcision, Dermatol. Surg., 34: 378-379, 2008.

23- Fife D. and Zachary C.B.: Combining Techniques for Treating Acne Scars, Curr. Derm. Rep., 1: 82-88, 2012.

24- Ceran C., Aksam E., Cicek C., Tezcan S., et al.: A new technique for correction of tethered and depressed scars: Layered dermal support, Aesth. Plast. Surg., 40: 749-754, 2016.

25- Pallua N., Pulsfort A.K., Suschek C. and Wolter T.P.: Content of the growth factors bFGF, IGF-1, VEGF, and PDGF-BB in freshly harvested lipoaspirate after centrifugation and incubation. Plast. Reconstr. Surg., 123: 826833,2009

26- Pallua N., Baroncini A., Alharbi Z. and Stromps J.P.: Improvement of facial scar appearance and microcirculation by autologous lipofilling, J. Plast. Reconstr. Aesthet. Surg., 67: 1033-1037, 2014.

27- Harandi S.A., Balighi K, Lajevardi V. and Akbari E.: Subcision suction method: a new successful combination therapy in treatment of atrophic acne scars and other depressed scars. J. Eur. Acad. Dermatol. Venereol., 25 (1): 92-99, 2011.

28- Adly A.O., Elbadawy M.A., Ashraf H. Abbas A.H., Mohamedy I.M. and Maati T.A.: Core fat graft injection in depressed scar augmentation. Egypt, J. Plast. Reconstr. Surg., 35 (2): 221-226, 2011. 